\title{
Stabilization of Wind Generator by Using STATCOM/SMES
}

\author{
M. R. I. Sheikh ${ }^{1}$ and S. M. A. Razzak ${ }^{2}$ \\ ${ }^{1}$ Kitami Institute of Technology, Hokkaido, Kitami, Japan \\ ${ }^{2}$ University of the Ryukyus, Okinawa, Japan
}

Received 3 June 2009, accepted in final revised form 8 August 2009

\begin{abstract}
In this work, the STATCOM/SMES system with a voltage-source IGBT converter is modeled as a controllable energy source. The objective of the proposed STATCOM/SMES topology is to provide both active and reactive power, which can significantly decrease the voltage and power fluctuations of grid connected fixed speed wind generators. One major problem in wind generator output power smoothing is setting of the reference output power. Constant output power reference is not a good choice because there can be some cases where wind speed is very low and then sufficient power cannot be obtained. In that case, energy storage device can solve the problem but large energy capacity may be needed. To generate output power reference, a Simple Moving Average (SMA) technique is used which corresponds to the energy storage capacity. Thus the capacity of SMES can be small $(50 \%$ of wind farm capacity). Real wind speed data is used in the simulation analyses, which validates the effectiveness of the proposed control strategy.
\end{abstract}

Keywords: STATCOM/SMES; Energy storage system (ESS); Simple moving average (SMA); Fixed speed wind generator; Voltage source converter (VSC).

(C) 2009 JSR Publications. ISSN: 2070-0237 (Print); 2070-0245 (Online). All rights reserved.

DOI: $10.3329 /$ jsr.v1i3.2605

J. Sci. Res. 1 (3), 528-538 (2009)

\section{Introduction}

One of the most important requirements during the operation of the electric power system is the operation security. This concept is related to the system capability of maintaining its operation in case of an unexpected failure of some of its components (e.g.: lines, generators, transformers, etc.). Hereof, it is derived the necessity of having available enough "short-term generation reserve" in order to preserve acceptable security levels. This reserve must be appropriately activated by means of the frequency control in order to keep the system frequency above the acceptable minimum level during the transient. Otherwise, serious problems [1] could occur in the utility system. Nowadays, the new energy storage systems (ESS) are a feasible alternative to decrease the reserve power of

\footnotetext{
${ }^{1}$ Corresponding author: ris_ruet@yahoo.com
} 
generators [2]. By using proper energy storage devices, excess energy may be stored to substitute the power reserve of generators during the action of the primary frequency control. In this sense, research in this field has been lately extended with the aim of incorporating power electronics devices into electric power systems. The goal pursued is to control the operation of the power system, a fact that clearly affects the operation security. In bulk power transmission systems, power electronics-based controllers are frequently called Flexible AC Transmission Systems (FACTS). Presently, these devices are a viable alternative as they allow to control voltages and currents of appropriate magnitude for electric power systems at an increasingly lower cost [2].

Voltage or current source inverter based FACTS devices such as static var compensator (SVC), static synchronous compensator (STATCOM), dynamic voltage restorer (DVR), solid state transfer switch (SSTS) and unified power flow controller (UPFC) have been used for flexible power flow control, secure loading and damping of power system oscillation [3-5]. But FACTS/ESS, i.e., FACTS with energy storage system (ESS) have recently emerged as more promising devices for power system applications [6]. Of these, superconducting magnetic energy storage systems (SMES), have received much attention among the researcher. The SMES is well known to be a system where energy is stored within a magnet that is capable of quickly releasing megawatt amounts of power. Thus SMES applications have been considered as new options to solve a variety of transmission, generation, and distribution system problems including improvement of voltage and angular stability, increasing power transfer capability of existing grids, damping subsynchronous oscillations, damping inter-area oscillations, load leveling etc. [7-8]. The SMES system is combined with the voltage-source IGBT converter is capable of effectively controlling and near instantaneously injecting both active and reactive power into the power system. Thus it can enhance the controllability and provides operation flexibility to a power system and is therefore a prospective option in building a FACTS.

The current article proposes a model of a STATCOM/SMES and a control algorithm for this combined system to minimize voltage and power fluctuations of wind generator during random wind speed variations. Considering these viewpoints, the proposed control strategy is a very effective way of stabilization of wind generator as well as entire power system.

\section{Wind Turbine Modeling}

Modeling of wind turbine rotor is complicated. According to the blade element theory [9], modeling of blade and shaft needs complicated and lengthy computations. Moreover, it also needs detailed and accurate information about rotor geometry. For that reason, considering only the electrical behavior of the system, a simplified method of modeling of the wind turbine blade and shaft is normally used [10]. The mathematical relation for the mechanical power extraction from the wind can be expressed as follows:

$$
P_{w}=0.5 \rho \pi R^{2} V_{w}^{3} C p(\beta, \lambda),
$$


where $P_{w}$ is the extracted power from the wind, $\rho$ is the air density $\left[\mathrm{kg} / \mathrm{m}^{3}\right], R$ is the blade radius [m] and $C_{p}$ is the power coefficient, which is a function of both tip speed ratio, $\lambda$ and blade pitch angle, $\beta$ [deg]. The $\lambda$ and $C_{p}$ equation has been taken from [11].

$$
\begin{aligned}
& \lambda=\frac{V_{w}}{\omega_{B}}, \\
& C_{p}=\frac{1}{2}\left(\lambda-0.022 \beta^{2}-5.6\right) e^{-0.17 \lambda,}
\end{aligned}
$$

Eq. (3) indicates the $C_{p}-\lambda$ characteristices, where, $\omega_{B}$ is the rotational speed of turbine hub $[\mathrm{rad} / \mathrm{s}]$. Here wind speed, $V_{w}$, is in mile/hr. The $C_{p}-\lambda$ curves are shown in Fig.1 for different values of $\beta$. When the wind velocity exceeds the rated speed then needed to control the pitch angle of the blade.

The pitch servo as shown in Fig. 2 is modeled with a first order delay system with a time constant $T_{d}$, of $5 \mathrm{sec}$. Because of the pitch actuation system cannot, in general, respond instantly, a rate limiter with a value of $10 \% \mathrm{sec}$ is added. Now the turbine torque, $T_{w}$, can be calculated from Eq. (4).

$$
\mathrm{T}_{\mathrm{w}}=0.5 \rho \pi \mathrm{R}^{2} \mathrm{~V}_{\mathrm{W}}^{2} \mathrm{Cp}(\beta, \lambda) / \lambda \text {, }
$$

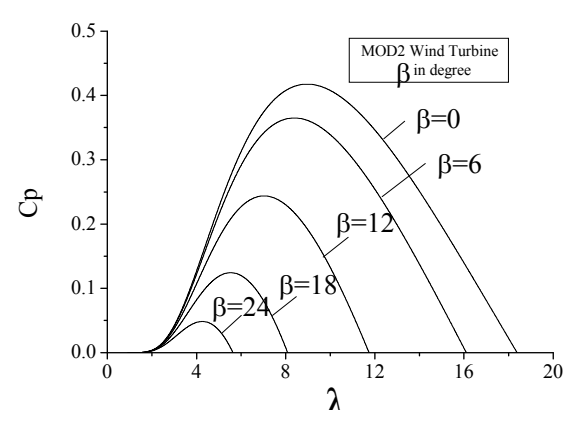

Fig. 1. $\mathrm{C}_{\mathrm{P}^{-}} \lambda$ curves for different pitch angles.

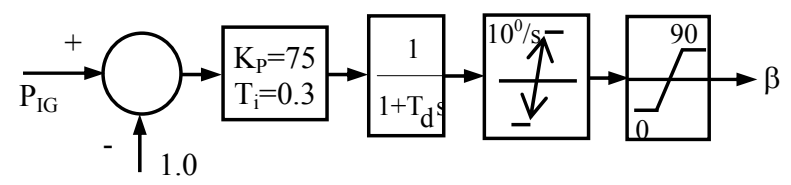

Fig. 2. Pitch angle controller.

\section{Model System}

Fig. 3 shows the model system where one synchronous generator (SG 100MVA) is connected to infinite bus through transformers and a double circuit transmission lines. The line parameters are numerically shown in the form of $R+j X$. One induction generator (IG 
50 MVA) is connected with the network via a transformer and a short transmission line. To establish the rotating magnetic field of the stator, reactive power is needed to be supplied from the network to the stator winding of the induction generator. So to compensate the reactive power demand at steady state, a capacitor bank is inserted at the terminal of IG [12-14]. The value of the capacitor $C$ is so chosen that the power factor of the wind power station becomes unity when it is operating in the rated condition $(V=1.0$, $P=0.5$ ). The SMES unit is connected at the induction generator terminal bus. The AVR (Automatic Voltage Regulator) and GOV (Governor) control system models for the synchronous generator and the generator parameters are same as those used in ref. [15]. Table 1 shows the parameters of generators.

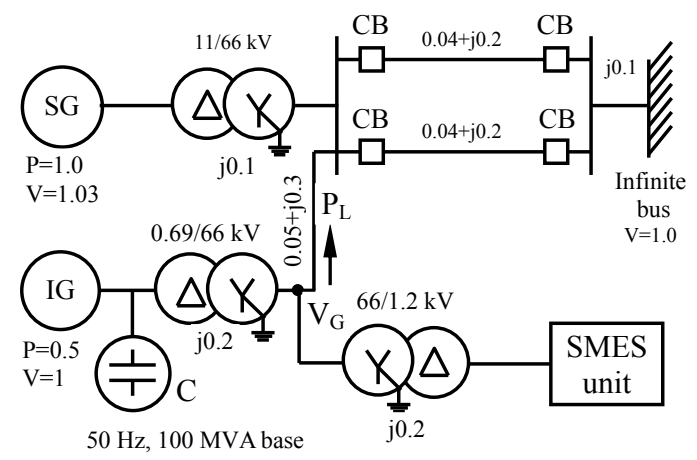

Fig. 3. Power system model.

Table 1. Generator parameters.

\begin{tabular}{llll}
\hline \multicolumn{3}{c}{ SG } & \multicolumn{2}{c}{ IG } \\
\hline $\mathrm{MVA}$ & 100.0 & $\mathrm{MVA}$ & 50.0 \\
$\mathrm{Ra}(\mathrm{pu})$ & 0.003 & $\mathrm{r} 1(\mathrm{pu})$ & 0.01 \\
$\mathrm{Xa}(\mathrm{pu})$ & 0.13 & $\mathrm{X} 1(\mathrm{pu})$ & 0.10 \\
$\mathrm{Xd}(\mathrm{pu})$ & 1.20 & $\mathrm{Xmu}(\mathrm{pu})$ & 3.50 \\
$\mathrm{Xq}(\mathrm{pu})$ & 0.70 & $\mathrm{r} 21(\mathrm{pu})$ & 0.035 \\
$\mathrm{Xd}(\mathrm{pu})$ & 0.30 & $\mathrm{x} 21(\mathrm{pu})$ & 0.030 \\
$\mathrm{Xq}(\mathrm{pu})$ & 0.228 & $\mathrm{r} 22(\mathrm{pu})$ & 0.014 \\
$\mathrm{Xd}{ }^{\prime \prime}(\mathrm{pu})$ & 0.22 & $\mathrm{x} 22(\mathrm{pu})$ & 0.098 \\
$\mathrm{Xq}{ }^{\prime \prime}(\mathrm{pu})$ & 0.25 & $\mathrm{H}(\mathrm{sec})$ & 1.50 \\
$\mathrm{Td} 0^{\prime}(\mathrm{sec})$ & 5.00 & & \\
$\mathrm{Td} 0^{\prime \prime}(\mathrm{sec})$ & 0.04 & & \\
$\mathrm{Tq} 0^{\prime \prime}(\mathrm{sec})$ & 0.05 & & \\
$\mathrm{H}(\mathrm{sec})$ & 2.50 & & \\
\hline
\end{tabular}

\section{STATCOM/SMES Topology}

\subsection{Integration of a SMES system with a STATCOM}

A Static Synchronous Compensator or STATCOM is a shunt-connected device, which injects reactive current into the $\mathrm{AC}$ system. This leading or lagging current, which can be controlled independently of the AC system voltage, is supplied through a power 
electronics based variable voltage source. The STATCOM does not employ capacitor or reactor banks to produce reactive power as the Static VAR Compensators (SVC) do. In the STATCOM, the capacitor is used to maintain a constant DC voltage in order to allow the operation of the voltage-source converter. A STATCOM controller with SMES is similar to an ideal synchronous machine, which generates a balanced set of (three) sinusoidal voltages at the fundamental frequency, with controllable amplitude and phase angle. This ideal machine has no inertia, its response is practically instantaneous, it does not significantly alter the system impedance, and it can internally generate reactive (both capacitive and inductive) power. Furthermore, it can exchange dynamically active power with the AC system if it is coupled to an appropriate energy source that can supply or absorb this power. The functional model of a STATCOM integrated with energy storage is shown in Fig. 4. The basic component of the STATCOM/SMES is the voltage-source converter (VSC) with semiconductors devices having turn-off capabilities (typically IGBTs).

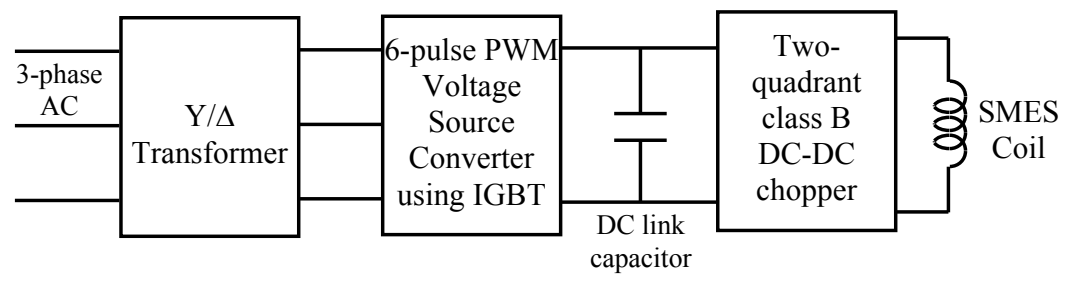

Fig. 4. Basic components of the STATCOM/SMES unit.

\subsection{PWM-VSC modeling}

In this study, the well-known cascade control scheme with independent control of the active and reactive current was developed as shown in Fig. 5. The aim of the control is to

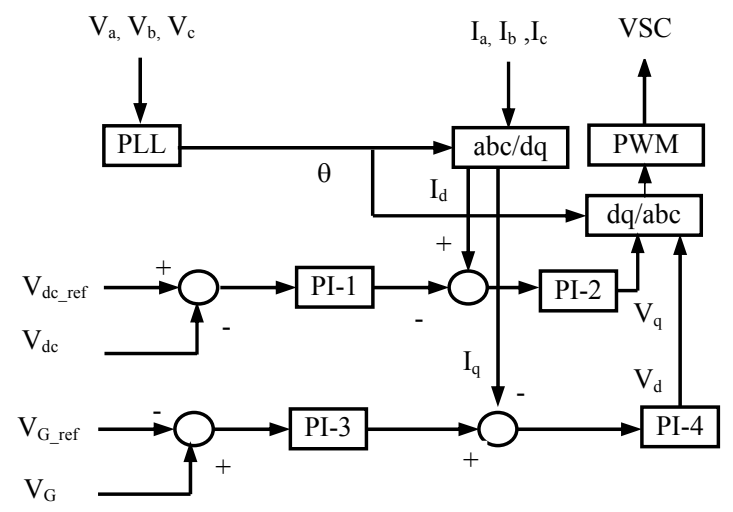

Fig. 5. Control system of the VSC.

maintain the magnitude of voltage at the wind farm terminal to be at the desired level. The DC link voltage $\left(\mathrm{V}_{\mathrm{dc}}\right)$ is also kept constant at the rated value. Finally, the three-phase 
reference signals are compared with the triangular carrier wave signal in order to generate the switching signals for the IGBT-switched VSC. High switching frequencies $(3 \mathrm{kHz})$ can be used to improve the efficiency of the converter. The DC link voltage is $2 \mathrm{kV}$, which is maintained constant throughout. The SMES is coupled to the $66 \mathrm{kV}$ line by a single step-down transformer $(66 / 1.2 \mathrm{kV})$ with $0.2 \mathrm{pu}$ leakage reactance (base value 100 MVA). The DC link capacitor value is $50 \mathrm{mF}$ [3].

\subsection{Two-quadrant DC-DC chopper}

Depending upon the values of chopper duty cycle $\mathrm{D}$, three regions of operation can be identified for the chopper arrangement. These regions of operation are known as charge/discharge/standby operation. The average voltage appearing across the SMES coil and chopper current at any instant of time can be represented by (5) [16],

$$
\begin{aligned}
& V_{S M \_a v}=[1-2 D] V_{d c \_a v} \\
& I_{d c \_a v}=[1-2 D] I_{S M \_a v}
\end{aligned}
$$

where $\mathrm{V}_{\mathrm{SM} \_ \text {av }}$ is the average voltage across the SMES coil, $\mathrm{I}_{\mathrm{SM} \_ \text {av }}$ is the average current through the SMES coil, $V_{\mathrm{dc} \_ \text {av }}$ is the average dc source voltage, $\mathrm{I}_{\mathrm{dc} \_ \text {av }}$ is the average $\mathrm{dc}$ source current, and $\mathrm{D}$ is the duty cycle of the chopper $(\mathrm{D}=\mathrm{IGBT}$ conduction time/period of one switching cycle).

Adjusting the duty cycle of the GTO firing signals controls the rate of charging /discharging. Thus when the duty cycle is larger than 0.5 or less than 0.5 , the coil is either charging or discharging respectively. The control system for charging/discharging is shown in [10]. When the unit is on standby, the coil current is kept constant, independent of the storage level, by adjusting the chopper duty cycle to $50 \%$, resulting in the net voltage across the superconducting winding to be zero. In order to generate the gate signals for the IGBT's of the chopper, the PWM reference signal is compared with the saw tooth carrier signal as shown in Fig. 6. The frequency of the saw tooth carrier signal for the chopper is chosen $100 \mathrm{~Hz}$. The parameters of the PI controllers used in Fig. 5 and Fig. 6 are shown in Table 2.

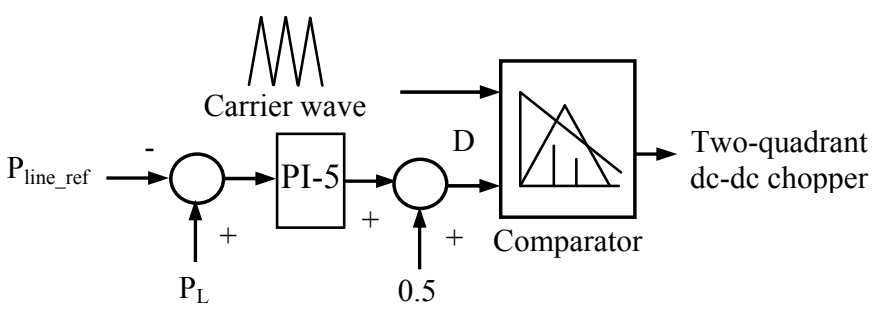

Fig. 6. Control system of two-quadrant dc-dc chopper. 
Table 2. Parameters of PI controllers.

\begin{tabular}{lccccc}
\hline & PI-1 & PI-2 & PI-3 & PI-4 & PI-5 \\
\hline $\mathrm{K}_{\mathrm{P}}$ & 1.0 & 0.1 & 1.0 & 0.1 & 1.0 \\
$\mathrm{~T}_{\mathrm{i}}$ & 0.02 & 0.002 & 0.02 & 0.002 & 0.02 \\
\hline
\end{tabular}

\subsection{Generation of reference line power $\left(P_{\text {line_ref }}\right)$}

Reference value of transmission line power $\mathrm{P}_{\text {line_ref }}$ is determined by using Simple Moving Average (SMA). The $\mathrm{n}$ period SMA [17] for period d is computed by:

$$
\mathrm{SMA}_{\mathrm{d}}=\frac{\sum_{\mathrm{i}=1}^{\mathrm{n}} \mathrm{M}_{(\mathrm{d}-\mathrm{i})+1}}{\mathrm{n}} ;(\mathrm{n} \leq \mathrm{d}),
$$

If ten measurements, $M_{1}$ through $M_{10}$ are available, the successive 4 period simple moving average, for example, are as follows:

$$
\begin{aligned}
& \mathrm{SMA}_{4}=\left(M_{4}+M_{3}+M_{2}+M_{1}\right) / 4, \\
& \left.\mathrm{SMA}_{5}=M_{5}+M_{4}+M_{3}+M_{2}\right) / 4, \\
& \mathrm{SMA}_{10}=\left(M_{10}+M_{9}+M_{8}+M_{7}\right) / 4 .
\end{aligned}
$$

It is not possible to compute a 4 period moving average until 4 periods data are available. That's why the first moving average in the above example is $\mathrm{SMA}_{4}$.

\section{Simulation Results}

Real wind speed data as shown in Fig. 7, which was obtained in Hokkaido Island, Japan, is used in the simulation, which is fluctuating in nature. The time step and simulation time have been chosen $0.00001 \mathrm{sec}$ and $600 \mathrm{sec}$ respectively. The simulations have been done by using PSCAD/EMTDC [18]. Two cases are considered to show the effectiveness of STATCOM/SMES topology for output power and terminal voltage smoothening.

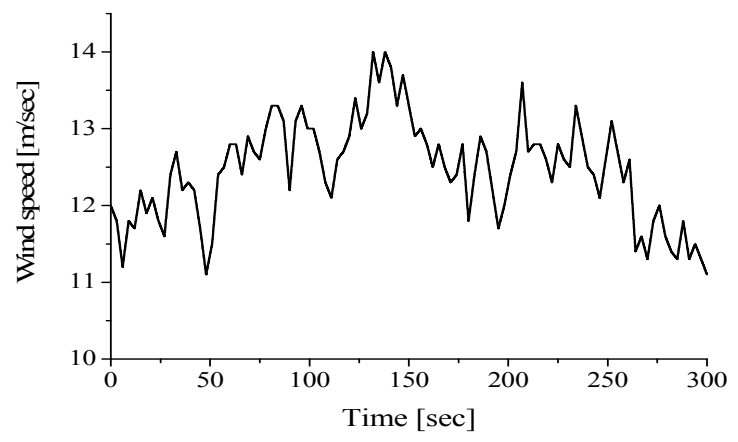

Fig. 7. Response of real wind data. 


\section{Case-1: Conventional pitch controller without STATCOM/SMES topology}

In this case, the conventional pitch controller is used to control the IG output power at rated level when the wind speed is above the rated speed. Fig. 8 and 9 show the real power and terminal voltage responses of induction generator, using only the conventional pitch controller. The wind turbine blade pitch angle response is also shown in Fig. 10. It is revealed that the conventional pitch controller cannot smooth well the wind generator output power and terminal voltage of induction generator.

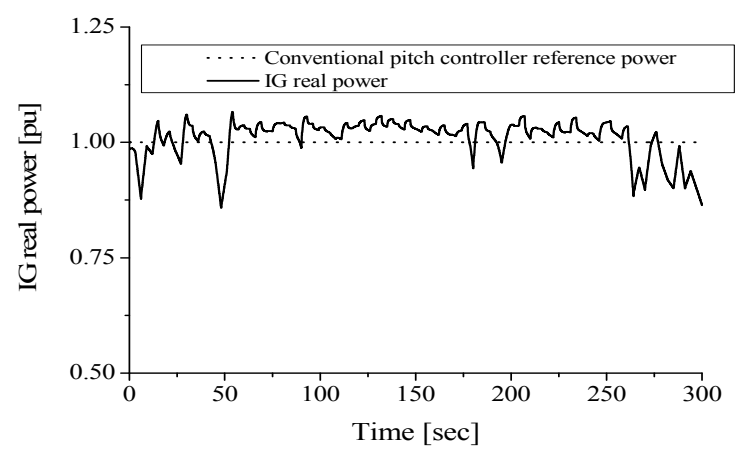

Fig. 8. Real power of IG with only conventional pitch controller.

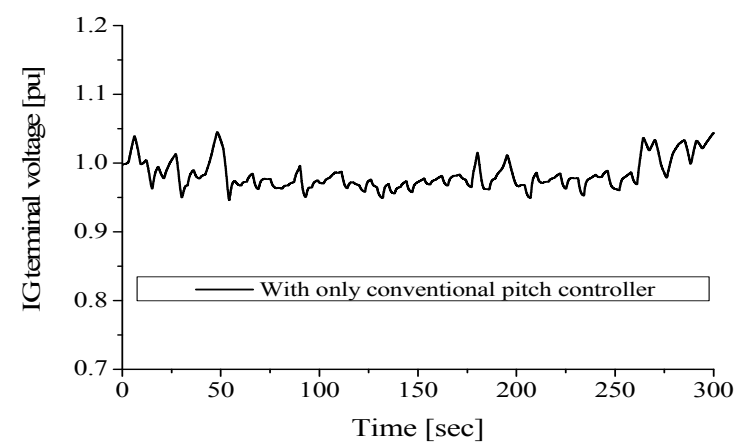

Fig. 9. Terminal voltage of IG with only conventional pitch controller.

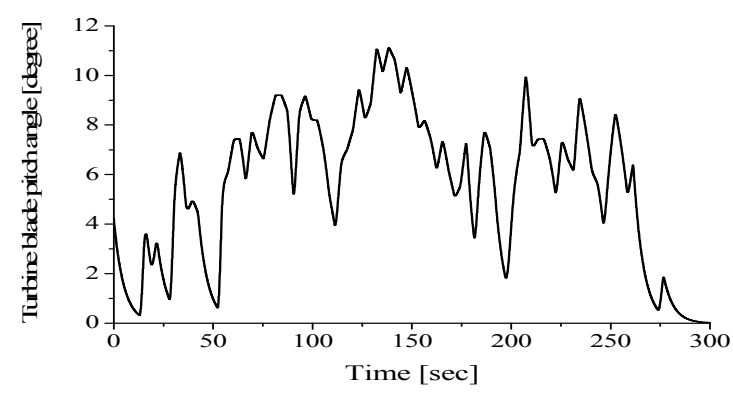

Fig. 10. Blade pitch angle of wind turbine. 


\section{Case-2: Conventional Pitch Controller with STATCOM/SMES Topology}

In this case, the effectiveness of the control strategy of STATCOM/SMES is demonstrated. Fig.11 shows the IG output power and reference line power responses in the case when STATCOM/SMES is connected to IG terminal bus in Fig. 3. In Fig.11, responses of the line power, and the real power of STATCOM/SMES unit are shown together. Fig. 12 shows the line power and SMES real power. It is clear that STATCOM/SMES can smooth the line power well according to the reference line power. In Fig. 13, the terminal voltage response of induction generator is presented when STATCOM/SMES is used. The STATCOM/SMES can provide necessary reactive power to maintain the constant voltage at wind generator terminal as shown in Fig. 14. Figure 15 shows the response of SMES voltage.

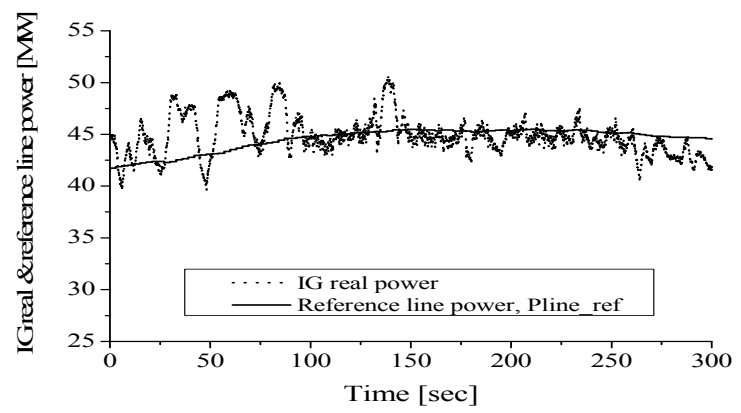

Fig. 11. Responses of IG real power and reference line power with STATCOM/SMES.

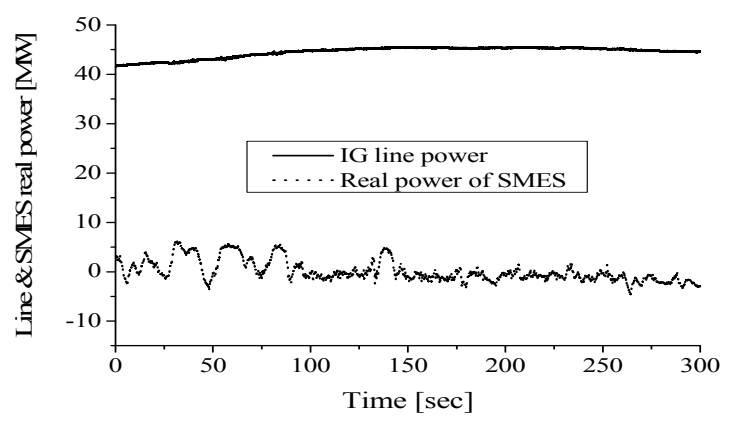

Fig. 12. Responses of IG line and SMES real power.

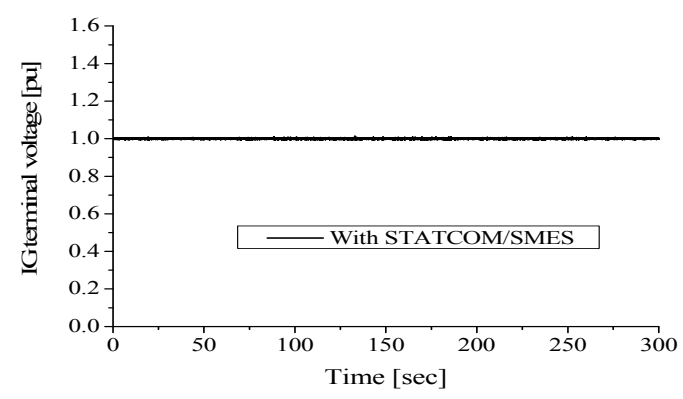

Fig. 13. Response of IG terminal voltage. 


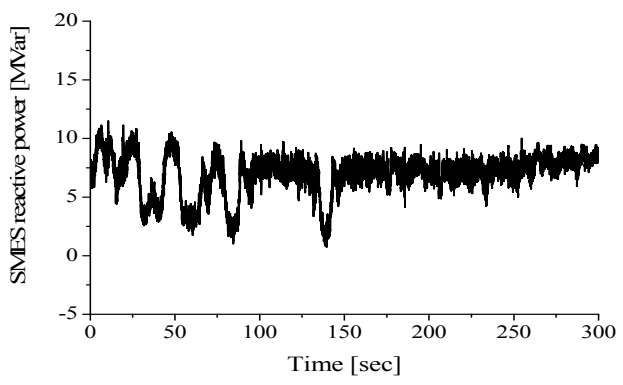

Fig. 14. Response of SMES reactive power.

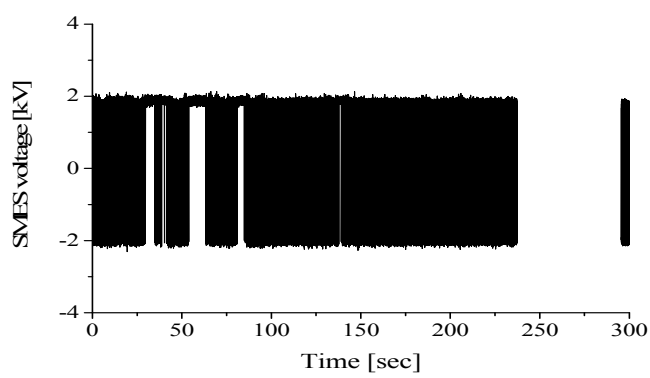

Fig. 15. Response of SMES voltage.

\section{Conclusions}

In this study, the control scheme of STATCOM/SMES topology for wind power application is presented. As wind is fluctuating in nature, the output power and terminal voltage of wind generator also fluctuate randomly. The proposed control system can smooth the wind generator output power. Moreover, it can also maintain constant voltage magnitude at wind farm terminal. Finally, the simulation results clearly show the suitability of the proposed control system of STATCOM/SMES topology for wind power application, especially in Japan in which wind speed varies more widely compared to Europe.

\section{References}

1. M. H. Ali, T. Murata, and J. Tamura, International Review of Electrical Engineering (IREE) 1 (4), 559 (2006).

2. T. Kinjo, T. Senjyu, N. Urasaki, and H. Fujita, IEEE Transaction on Energy Conversion 21 (1), 221(2006). doi:10.1109/TEC.2005.853752

3. L. Gyugyi, Unified Power-Flow Control Concept for Flexible AC Transmission Systems, IEE Proc.-C, 139(4), 323(1992).

4. L. Gyugyi, IEEE Trans. On Power Delivery 9 (2), 904 (1994). doi:10.1109/61.296273

5. H. F. Wang, F. Li, and R. G.Cameron, IEEE Proc.-Generation, Transmission and Distribution 146 (5), 409 (1999). doi:10.1049/ip-gtd:19990545

6. L. Zhang, C. Shen, M. L. Crow, L. Dong, S. Pekarek, and S. Atcitty, Electric Power Component and System 33 (3), 299 (2005). doi:10.1080/15325000590474438 
7. Y. Mitani, K. Tsuji, and Y. Murakami, IEEE Trans. Power System 3, 1418 (1988). doi:10.1109/59.192948

8. S. Banerjee, J. K. Chatterjee, and S. C. Tripathy, IEEE Trans. on Energy Conversion 5, 46 (1990). doi: $10.1109 / 60.50811$

9. P. M. Anderson, A. Bose., IEEE Transactions on Power Apparatus and Systems PAS-102: 3791 (1983). doi:10.1109/TPAS.1983.317873

10. M. R. I. Sheikh, S. M. Muyeen, R. Takahashi, T. Murata, and J. Tamura, International Review of Automatic Control (IREACO) 1(3), 311 (2008). doi:10.1541/ieejpes.126.742

11. S. Heier, Grid Integration of Wind Energy Conversion System (John Wiley \& Sons Ltd., Chicester, UK, 1998).

12. S.M. Muyeen, Mohd. Hasan Ali, Rion Takahashi, Toshiaki Murata, and Junji Tamura, IEEJ Transaction on PE, 126(8), 742 (2007).

13. S. M. Muyeen, R. Takahashi, T. Murata, and J. Tamura, Transient Stability Enhancement of Wind Generator by Online Logical Pitch Controller with the Consideration of Initial Condition Settings, Proceeding of the IPEC (CDROM, 2005).

14. C.L. Souza, L.M. Neto, G.C. Guimaraes, and A.J. Moraes, Power System Transient Stability Analysis Including Synchronous and Induction Generator, IEEE Porto Power Tech. Proceedings, 2, (2001).

15. M.R.I. Sheikh, S.M. Muyeen, Rion Takahashi, Toshiaki Murata, and Junji Tamura "Transient Stability Enhancement of Wind Generator Using Superconducting Magnetic Energy Storage Unit", International Conference of Electrical Machine (Conference CDROM, 2008).

16. IEEE Task Force on Benchmark Models for Digital Simulation of FACTS and Custom-Power Controllers, T\&D Committee, IEEE Trans. Power Delivery 21 (2), 699(2006).

17. S.M. Muyeen, T. Murata, and J.Tamura, "Stability Augmentation of Grid Connected Wind Farm", Springer Verlag-London, ( 2008).

18. PSCAD/EMTDC Manual, Manitoba HVDC Research Center (1994). 